\title{
Carl Schmitt y el pensamiento del orden concreto: una crítica de la interpretación decisionista de la teología política schmittiana
}

\section{Carl Schmitt and the concrete-order thinking: a critique of the decionist interpretation of Schmitt's political theology}

\author{
RoBERTO NAVARRETE
}

Universidad Autónoma de Madrid

RESUMEN. El presente artículo ofrece una crítica de la interpretación decisionista de la doctrina de la soberanía postulada por C. Schmitt en Teología política. Partiendo de la teoría de la secularización del jurista alemán, se mostrará que la capacidad de decisión sobre el estado de excepción definitoria del soberano schmittiano no es absoluta sino que permanece determinada por un orden concreto inmanente cuya representación es tarea del Estado. Así, se pondrá en cuestión la raigambre hobbesiana de la teología política schmittiana, deudora en mayor medida de la teoría hegeliana del Estado, y se presentará la razón jurídico-política de la desavenencia de Schmitt con el nacionalsocialismo.

Palabras clave: teología política; soberanía; representación; decisión; orden concreto.

\section{Introducción}

La reconstrucción histórico-genealógica de la teoría moderna del Estado esbozada por Carl Schmitt en Teología política ofrece un diagnóstico de la Modernidad de acuerdo con el cual ésta estaría determi-
ABSTRACT. This paper presents a critique of the decisionist interpretation of the concept of sovereignty which Carl Schmitt proposes in Political Theology. Starting from Schmitt's theory of secularisation, I try to show that the capacity for decision on the state of exception which defines the Schmittian sovereign is not absolute but remains determined by an immanent concrete order that the State must represent. I question thereby the Hobbesian roots of Schmitt's political theology, which rather is in debt with Hegel's theory of the State, and I expose the juridic-political reason of Schmitt's disagreement with $\mathrm{Na}$ tional Socialism.

Key words: political theology; sovereignty; representation; decision; concrete-order.

nada tanto por el decisionismo de las primeras doctrinas modernas de la soberanía como, sobre todo, por un devenir que conduce desde el absolutismo hacia el liberalismo decimonónico y, ya en el siglo XX, hacia el positivismo jurídico propio de la teoría pura del derecho de H. Kelsen ${ }^{1}$. 
Esta victoria del racionalismo frente al voluntarismo -tanto revolucionario como contrarrevolucionario- escondería a ojos de Schmitt una derrota de lo político: una progresiva tendencia hacia la «despolitización» (Entpolitisierung), no ya de una determinada esfera de la actividad humana, sino de la existencia misma de aquel ser que Aristóteles definió precisamente como zoon politikon ${ }^{2}$.

El desarrollo histórico de la Edad Moderna significa en opinión de Schmitt una progresiva deshumanización paradójicamente puesta en marcha en nombre de la propia humanidad, esto es, de su emancipación respecto de las cadenas de la religión en primer lugar $\mathrm{y}$, posteriormente, de la metafisica y de la moral para, pasando por el endiosamiento estético-romántico del individuo, ir a parar en el siglo XX a la economificación y tecnificación de unas relaciones que ya sólo a duras penas pueden ser consideradas propiamente humanas ${ }^{3}$. Determinadas por la lógica del valor, parecen más bien apuntar en la dirección del final acelerado de una humanidad tecnificada, despolitizada y propiamente deshumanizada. Tal sería, a juicio del autor de Teología política, el pronóstico de la ideologización de lo moderno que olvida su propio origen trágico y frente a la que, a modo de diagnóstico, Schmitt ofrece su propia interpretación de la Modernidad como secularización de la teología así como, a modo de terapia, su propia teología política, esto es, la doctrina de la soberanía lacónicamente condensada por Schmitt en su célebre definición: «Soberano es quien decide sobre el estado de excepción» ${ }^{4}$.

Inmediatamente después de introducir su igualmente archiconocida tesis so- bre la secularización -es decir, su definición de teología política en sentido histórico-genealógico o su explicación de la peculiaridad de la Modernidad políticaSchmitt aduce, a modo de ejemplo que facilite su comprensión, una relación de analogía entre la capacidad divina para obrar milagros - excepciones a las leyes de naturaleza- y aquella que atribuye al soberano como rasgo definitorio suyo: la capacidad para suspender in toto un determinado ordenamiento jurídico. Esta analogía debe entenderse por tanto a la luz de la teoría schmittiana de la secularización y, en consecuencia, desde el presupuesto de la desdivinización moderna del mundo. Que «todos los conceptos pregnantes de la moderna teoría del Estado son conceptos teológicos secularizados $»^{5}$ significa que el Estado es análogo a Dios, si bien únicamente desde un punto de vista funcional, pues, desde el punto de vista de la sustancia, el ambito jurídico-político, a diferencia del teológico, se ubica en la más radical e inmediata ausencia de fundamento ${ }^{6}$. El papel del soberano, núcleo constructivo de la teología política schmittiana, no es otro que el de ofrecer una respuesta adecuada, según Schmitt, a esta situación que constituye el origen de lo moderno - la falta de un fundamento sustancial garante del orden del mundo- y que la propia Modernidad, como ideología que se realiza a través del parlamentarismo liberal, ha olvidado. La propuesta política de Schmitt, su doctrina de la soberanía, debió por tanto enfrentarse y ofrecer una alternativa, en primer lugar, al concepto fundamental en torno al cual opera dicho parlamentarismo, esto es, el concepto de «representación». 
Es sólo a partir de las consideraciones de Schmitt respecto de este problema que cabe entender la referida definición schmittiana del soberano, precisamente la tesis que ha llevado al jurista a ser general y erróneamente entendido, fundamentalmente desde el mencionado positivismo de corte kelseniano, como un defensor de la terrible arbitrariedad del puro decisionismo. Esta acusación, como se tratará de mostrar a continuación, es impugnada desde el momento en que se concibe adecuadamente aquello que liga los elementos representativo y decisionista de la doctrina schmittiana de la soberanía como respuesta, precisamente, a la pérdida moderna de toda auctoritas sustancial y a los problemas que ella plantea desde el punto de vista de la realización del derecho (Rechtsverwirklichung), es decir, del Estado como sustituto funcional del Dios pre-moderno y, por lo tanto, garante de un orden, ahora inmanente, que subyace y es previo a la propia institución estatal. La potentia decisoria de ésta no es, en esa misma medida, absoluta, sino ordinata ${ }^{7}$.

\section{Derecho, poder y representación}

Una exposición adecuada del núcleo práctico-operativo de la teología política schmittiana debe partir, por lo tanto, de su tratamiento del problema de la repraesentatio al que la lengua materna de Schmitt se refiere, a diferencia del castellano, por medio de al menos cuatro términos. En primer lugar, Darstellung, en el sentido de «poner» (stellen) algo «allí» $(d a)$, o «fuera» (ex), es decir, «ex-poner», motivo por el cual el término, afín a la repraesentatio similitudinis latina, se re- serva fundamentalmente para mentar representaciones de tipo artístico como, por ejemplo, un cuadro o una escultura, toda vez que éstas (re)presentan cosas de manera objetiva, esto es, realidades exteriores al sujeto que las contempla. Se emplea también, por la misma razón, para hacer referencia a las representaciones teatrales, si bien éstas son también significadas por el término Vorstellung, ya que aquello que se (re)presenta en el escenario puede ser considerado o no por el espectador como real, o sea, porque en verdad lo allí (re)presentado gana su propia realidad en la operación constructiva del sujeto que se dirige a ello intencionalmente. En efecto, vor pierde aquí su sentido preposicional como «delante» y Vorstellung, literalmente el efecto de un «poner delante» (vorstellen), se refiere más bien a una representación de tipo mental, es decir, al resultado de la mediación esquemática que permite el conocimiento en el sentido de la adaequatio rei et intellectus. Ni Darstellung ni Vorstellung poseen, entonces, un significado jurídico ni político, o al menos no directamente, por lo que ni el uno ni el otro son objeto de consideración por parte de Schmitt y sí, en cambio, de toda la tradición alemana estrictamente filosófica.

Desde el punto de vista de la teoría del derecho, la lengua alemana significa «representación» por medio de los términos Vertretung y Stellvertretung. Ambos son también empleados por los teóricos del moderno Estado de derecho, es decir de la democracia parlamentaria, para referirse a la función específica ejercida por aquellos que, libremente elegidos mediante sufragio, tienen en sus manos los poderes ejecutivo y legislativo del Estado. Los go- 
bernantes y parlamentarios de las democracias liberales son los encargados de ejercer la representación del pueblo (Volksvertretung) en las instituciones del Estado. La democracia parlamentaria es, en este sentido, tanto indirecta (indirekt) como representativa y, sin embargo, para referirse a este segundo aspecto, el término alemán empleado es repräsentativ. El problema jurídico-político de la representación se cifra, por lo tanto, en el significado de los términos Vertretung y Repräsentation. Éstos, en opinión de Schmitt, sólo determinados ideológicamente por el parlamentarismo pueden referirse a una y la misma cosa. Mientras que el primero es un concepto del derecho privado que sólo engañosamente puede ser elevado a categoría de derecho público, el segundo constituye propiamente un principio formal de toda existencia política de un pueblo y de un Estado ${ }^{8}$.

El vocablo alemán Vertretung mienta, en efecto, «representación» en el sentido de repraesentatio potestatis, es decir, de «delegación», pero también de «sustitución»e, incluso, de la «defensa» ejercida, por ejemplo, por un abogado con respecto a los intereses de su cliente: una persona privada que, precisamente, delega el poder de ejercer un derecho privado en su letrado, quien por su parte le sustituye, como su comisario, previo establecimiento de un contrato -o bien naturalmente, como en el caso de la relación entre padre e hijo: repraesentatio naturalis-. En este sentido, el contractualismo en el que se fundamentan los sistemas democrático-parlamentarios no pretendería sino elevar al ámbito de lo público este mismo procedimiento representativo: todos y cada uno de los individuos que integran una multitud pactarían en primer lugar entre sí, constituyéndose aparentemente como pueblo y, después, por vía electoral, con aquellos que los representan en las correspondientes instituciones, sólo aparentemente políticas. La articulación de la sociedad, esto es su representación, permanece en un nivel elemental que no permite que el pueblo, como unidad política propiamente dicha, adquiera verdaderamente existencia mediante una genuina coincidencia entre representante y representado (repraesentatio identitatis) ${ }^{9}$.

Pensada en los términos del parlamentarismo, la representación no deja de ser nunca una mera defensa de los intereses privados de todos y cada uno de los individuos que delegan en sus gobernantes, considerados como sustitutos suyos en el ámbito de «lo público». No ocurre, por tanto, que la Vertretung se eleve propiamente a categoría del derecho público, es decir a representación política del pueblo como un todo, sino más bien una privatización del espacio público o, cuando menos, una mezcla a todas luces nefasta de lo privado y de lo público. Schmitt distingue por ello entre «contrato social» (Sozialvertrag) y «pacto constitucional» (Verfassungsvertrag), así como entre «contrato como pacto libre» (freier Vertrag), propio del derecho privado, y «contrato como pacto de status» (Statusvertrag), propio del derecho público ${ }^{10}$. No es el pueblo como unidad política aquello que es representado por los parlamentos, sino cada individuo tomado aisladamente. Ni el pueblo ni, como representante político suyo, el Estado, existen como tales, pues no alcanzan aquella publicidad (Öffentlichkeit) 
que les es constitutiva. La representación, si aspira a ser verdaderamente política (Repräsentation), debe evitar toda contaminación conceptual por parte de la Vertretung si no quiere, de hecho, quedar reducida a mera Vorstellung, tanto en el sentido de «producto de la imaginación» como de «representación teatral».

Estas consecuencias despolitizadoras de las teorías contractualistas están a la base de las reservas de Schmitt en relación a la doctrina hobbesiana del Estado - de la que, por ende, no destacará tanto su teoría de la representación cuanto su componente decisionista, condensado en la fórmula Auctoritas non veritas facit legem-, así como de su afinidad con la concepción hegeliana del Estado como mediación racional que no tiene su origen en pacto alguno entre individuos sino en la relación Idea/contingencia y, por lo tanto, en el problema jurídico-político de la realización del derecho al que, como se verá de inmediato, se refiere según Schmitt el concepto de Repräsentation. La crítica de Schmitt al contractualismo entraña, asimismo, una crítica al positivismo jurídico, el cual reduce el fundamento de validez del derecho al significado de la fórmula pacta sunt servanda que, para el jurista de Plettenberg, carece de todo valor científico-juridico:

Antes bien, o es una completa duplicación e hipóstasis tautológica, o enuncia que el pacto concreto no vale, sino tan sólo la "norma" general de que los pactos valen. Adicionar a cada pacto en vigor la "norma" de que los pactos en general son válidos, es una vacua ficción, pues el pacto concreto vale y obliga jurídicamente por virtud del Derecho positivo y no por virtud de la norma pacta sunt servanda. Tales adiciones e hipóstasis ficticias son posibles en número ilimitado; toda norma vale, porque vale la norma general de que hay normas que deben valer, etc. Pero, para la fundamentación de una unidad política de existencia concreta, carecen por completo de significación ${ }^{11}$.

La privatizadora y, en esa misma medida, despolitizante Vertretung liberal conduce en última instancia, a ojos de Schmitt, hacia la estetización de la política por él denunciada en Romanticismo político (1919) y, tres años más tarde, al comienzo del cuarto de los capítulos de su Teología política, el dedicado precisamente al catolicismo político del que Schmitt toma los elementos polémicos no dogmáticos- que permiten, en su opinión, enfrentarse al problema jurídico-político planteado por la secularización, esto es, la pérdida de todo fundamento sustancial de los ordenamientos jurídicos ${ }^{12}$. En lugar de ofrecer una respuesta a esta cuestión, como correlato de la ideologización de la Modernidad contra la que justamente se dirige la interpretación schmittiana de lo moderno, la representación entendida como Vertretung niega la necesidad del Estado como forma jurídico-política de los pueblos, reducidos así a meros conjuntos de subjetividades desprovistos de todo orden, es decir, a un cúmulo de individuos endiosados tanto como deshumanizados: desprovistos de toda relación política con la realidad, otrora determinada por el Dios de la revelación y, en puridad, 
por la institución que, cristológicamente dotada de autoridad espiritual, ejercía la labor de su representación (Repräsentation) en la tierra: la Iglesia como institución visible.

Aunque probablemente quepa encontrar en las páginas ya citadas de Teoría de la Constitución la exposición más acabada y sistemática de la teoría de la representación de Schmitt, así como, por lo tanto, de su respuesta a la despolitización efectuada por el liberalismo, la atención debe dirigirse, en razón del carácter teológico-político constitutivo de la doctrina schmittiana de la soberanía, hacia aquellos trabajos de Schmitt en los que el jurista de Plettenberg tematiza el problema de la repraesentatio desde el punto de vista de la analogía entre la Iglesia y el Estado, es decir, desde la perspectiva de su interpretación de la moderna teoría del Estado como el resultado de una secularización de conceptos teológicos. Tal es, en efecto, su respuesta a la ideologización de la Modernidad, a su no confesado secularismo, cuya expresión «política» encuentra Schmitt en el parlamentarismo y su teoría de la representación.

Debe advertirse, empero, el hecho de que el correlato establecido por Schmitt entre lo eclesiástico y lo jurídico-político - al menos tal y como lo formuló en la época de Weimar-, al igual que su interés en la filosofía católica de la contrarrevolución, no está determinado dogmáticamente, es decir en su sustancia, sino tan sólo funcionalmente. El carácter confesional del catolicismo schmittiano ocupa en su teología política un lugar secundario con respecto al derecho. Sus elogios de la Iglesia católica y romana deben ser leídos en esta perspectiva, es decir, considerándolos a partir de una construcción conceptual de orden preminentemente político, no teológico ni confesional. Aunque intempestivo, el jurista Schmitt fue un hombre de su tiempo, dotado de sentido histórico y, por ello, defensor de la especificidad de lo moderno. Aquellas obras de juventud a las que se prestará atención a continuación no identifican sin más Iglesia y Estado, en el sentido de que lo político deba ser dejado en manos de la institución a la que se refiere el primer término de la analogía, sino que confieren a la Iglesia el papel de modelo funcional de la institución estatal. No se trata, por lo tanto, de que el Estado, concebido como realidad plenamente secular -tanto «de» este mundo como «en» este mundo-, represente aquello que representa la Iglesia, sino que la representación por él llevada a cabo cumpla la misma función que la eclesiástica, a saber, la visibilización de algo «invisible»-que ya no es Dios- con vistas a satisfacer, siquiera en la medida de lo posible, la exigencia de orden constitutiva de la política. Se trata en definitiva de que la representación efectuada por el Estado lo sea en el sentido de Repräsentation y ya no de mera Vertretung. En ello se cifra la defensa schmittiana del catolicismo y su Iglesia, de su capacidad para formar figuras que representen lo trascendente en lo inmanente, en la cual Schmitt encuentra las notas paradigmáticas de su alternativa a la no-politicidad liberal.

Tanto es así que, de hecho, en el $\mathrm{Ha}$ bilitationschrift de Schmitt, El valor del Estado y el significado del individuo (1914), lo jurídico cuya realización permite el Estado en tanto que instancia me- 
diadora (representativa), está dotado de un carácter trascendente que, en conformidad con su tesis sobre la secularización, habrá de ser «corregido» por el jurista con el paso de los años, hasta inmanentizarlo por completo a través, primero, de la idea de «normalidad fáctica» (faktische Normalität), más tarde del concepto de «lo político» (das Politische) como presupuesto del Estado y, por último, del de «orden concreto» (Konkretordnung). Lo decisivo es, sin embargo, que ya en este texto, consagrado al problema de la realización del derecho, Schmitt otorga al Estado la capacidad, análoga a la de la Iglesia, de representar en la praxis política concreta aquello que le precede, es decir, de mediar entre el Derecho (Recht) y el Poder (Macht), de modo análogo a como la Iglesia media entre el Reino y el mundo. Ni la representación, por lo tanto, se juega entre individuos, como en el caso de la Vertretung del liberalismo clásico, ni el derecho se disuelve en el Estado, como en el caso del positivismo kelseniano, que de este modo renuncia más o menos conscientemente a plantear la cuestión del origen del orden jurídico, es decir de la legitimidad de la ley y, con ella, la de la propia Modernidad. Schmitt, en cambio, problematiza esta cuestión en toda su radicalidad mediante el reconocimiento de una discontinuidad entre el Derecho $(R e c h t)$ y su realización concreta (Macht) que el Estado, como instancia de representación (Repräsentation), salva siempre, aun de manera imperfecta $\mathrm{y}$, por lo tanto, en todo caso provisional ${ }^{13}$. Repräsentation, función definitoria del Estado, significa entonces Rechtsverwirklichung: realización de un derecho ca- rente de fundamento sustancial o plenamente racional alguno y, en esa misma medida, radical e inmediatamente abierto al desorden, es decir, a la excepción.

El elemento decisionista, irracionalista $\mathrm{y}$, de hecho, existencialista del núcleo práctico-operativo de la teología política schmittiana entra aquí en escena. Antes de hacer referencia a él, a pesar de que como el propio Schmitt indica a los lectores de Teología política (1922) la analogía entre los conceptos jurídicos y teológicos está efectivamente presente en El valor del Estado (1914), de hecho de modo más protagonista que en Romanticismo político (1919) y que en La dictadura (1921), no se debe dejar de hacer mención a Catolicismo romano y forma política (1923), pues es en este trabajo en el que verdaderamente Schmitt eleva la Iglesia a la condición de modelo para el Estado como instancia de Repräsentation, esto es, de realización de una idea ${ }^{14}$.

Heredera del racionalismo institucional y jurídico del Imperio Romano, con el que guardaría una relación de estricta continuidad, en efecto, la Iglesia es presentada aquí por Schmitt como persona jurídica por excelencia en virtud, justamente, de su incomparable capacidad para formar figuras representativas, esto es, para visibilizar una Idea que en su caso es «Dios» pero que, en el del Estado, bien podría ser «pueblo» ${ }^{15}$. La diferencia entre ambas instituciones reside en que, mientras que la capacidad de la Iglesia para adoptar una forma jurídica (Rechtsform) es absoluta, la del Estado aparece constantemente cuestionada por su contrario, lo informe. Aquella está dotada de una sustancia teológica fundante, «Dios» o «Dios hecho Hom- 
bre», aspirando así a abarcarlo todo, a ser complexio oppositorum, mientras que el Estado está siempre expuesto, en razón de la secularización, a fuerzas contrapuestas que atentan contra el orden por él representado. Mientras que la Iglesia es capaz de conciliar «esto y lo otro» (Sowohl-Als), el Estado debe necesariamente conformarse con decidir entre «o lo uno o lo otro» (Entweder-Oder) ${ }^{16}$.

Aun emulándola, el Estado, absolutamente mundano, no puede aspirar al elemento glorioso de una ecclesia triumphans, es decir, a la visibilización del Absoluto $^{17}$. Por el contrario, está siempre marcado por un elemento trágico: su enfrentamiento constitutivo con el desorden al que precisamente trata de dar respuesta para de este modo cumplir en la medida de sus posibilidades con el difícil papel de sustituto funcional del Dios medieval. Dicho elemento trágico es precisamente el enfatizado por Schmitt en $T e$ ología política por medio de su definición de la soberanía como capacidad para decidir sobre el estado de excepción, así como en El concepto de lo político, a través de la distinción «amigo/enemigo» (Freund/Feind) pero también, en relación a lo eclesiástico mismo, en el artículo sobre La visibilidad de la Iglesia, a través en este caso de la distinción entre «Iglesia oficial» (offizielle Kirche) e «Iglesia visible» (sichtbare Kirche) ${ }^{18}$.

Frente al optimismo manifestado por Schmitt en su elogium del catolicismo, en este artículo de 1917, consagrado también, no obstante, a la exaltación de la ejemplaridad jurídico-formal de la Iglesia y por lo tanto de la capacidad representativa de un Papado cristificado, el jurista ya habilitado tematiza abiertamente la posibilidad de que también en el caso de la Iglesia se dé una oposición o, al menos, un desajuste entre la pura facticidad del representante concreto (el summus pontifex como caput de un cuerpo político) y lo representado (Dios, o Dios hecho hombre: Cristo como caput de su propio cuerpo místico): una falta de legitimidad, no ciertamente del Papado, o de la Iglesia visible, sino de un determinado papa y del modo en que éste hace efectiva la visibilización de la Idea, esto es, la Iglesia oficial ${ }^{19}$.

En tanto que civitas mundi, la ecclesia militans o malignatium, como el Estado en relación al Derecho en el Habilitationsschrift, resulta siempre incapaz de llevar a cumplimiento la auténtica Iglesia visible, la ecclesia triumphans o bonorum que, como genuina civitas Dei, representa de manera perfecta lo Absoluto. Sin embargo, en el caso del Estado no hay propiamente absoluto alguno que representar ni, por lo tanto, Estado auténtico, sino tan sólo Estados, es decir, realidades histórico-fácticas concretas. El protestantismo es entonces legítimo, en dogmática -aquí sí- opinión de Schmitt, nunca como posibilidad religiosa, sino únicamente como posibilidad política, es decir, no como negación de la divina Iglesia visibile (corpus mysticum) sino tan sólo de su concreción como Iglesia humana (corpus politicum) ${ }^{20}$.

En contraposición a la Iglesia, la humanidad constitutiva del Estado moderno, su secularidad y, por lo tanto, profanidad, se pone de manifiesto en la teología política schmittiana no sólo por medio de la afirmación de la existencia de una desconexión originaria entre Recht y Macht 
sino, fundamentalmente, a través de la desustanciación o indeterminación radical del Derecho afirmada por Schmitt, si no en 1914, desde luego sí en 1922 y desde entonces en adelante. Ningún atisbo hay, por tanto, de ius divinum o ius naturale en la doctrina schmittiana de la soberanía, como tampoco de autofundamentación legal (racional) de lo jurídico, sino precisamente el recuerdo del origen trágico de la Modernidad: la pérdida de toda legitimación trascendente de lo político, es decir, de toda auctoritas en sentido premoderno. De ella se sigue, de acuerdo con la teoría schmittiana de la Rechtsverwirklichung, la necesidad de sustituir la mediación pontificia tradicional entre Cielo y Tierra, no por una jugada únicamente entre individuos siempre presentes, sino por una forma de representación capaz de hacerse cargo conscientemente de la imposibilidad de todo tránsito perfecto entre lo justo y lo legal en razón del carácter absolutamente indeterminado, privado de toda sustancia, del primero. La auctoritas del soberano schmittiano se separa así, desde el punto de vista de su contenido, tanto de la Vertretung liberal como de la representación cristológica basada en el dogma de la Encarnación. Su necesidad es efecto, por lo demás, tanto del fracaso histórico de la Iglesia, puesto de manifiesto ya por el surgimiento del protestantismo, como de la incapacidad del moderno Estado de derecho para ofrecer una respuesta adecuada -mejor sería decir, «legítima», y no simplemente «legal»-al fiasco y la falla, ideológicamente olvidados por el parlamentarismo, en los que se ubica el principio de la Modernidad.

\section{Excepción, decisión y orden concreto}

A la falta de fundamento de lo real que caracteriza a la Edad Moderna debe replicar en el plano político, según Schmitt, no una legalidad fantasmalmente fundada en sí misma y, en esa misma medida, desfondada, sino una legalidad (norma) legitimada por una decisión tomada por la voluntad no a partir de un orden eterno que la precede quiméricamente -el ius divinonaturale que determina sustancialmente las decisiones tomadas por el Pontifex Maximus cristiano como infalible intérprete de la revelación- sino sobre aquello que efectivamente está antes que ella: la más absoluta falta de orden (excepción). La esencia de la existencia política moderna - la soberanía - se cifra así, de acuerdo con la teología política schmittiana, tanto en el ser representado como en el ser decidido aquello que ha de ser representado, es decir, en un decidirse por aquello que ha de ser representado o una decisión para la representación que no puede decidir a partir de nada, sino sobre la nada: el desorden contra el que la soberanía está llamada a combatir mediante la representación, esto es, la realización de un sistema normativo que, carente de toda sustancia fundante pre-moderna, permite no obstante ordenar racionalmente la existencia de un pueblo, irracional qua existencia, y, así, darle forma jurídica como unidad política ${ }^{21}$. He aquí la diferencia entre «Soberanía» y «Papado», así como la razón de ser de la famosa definición schmittiana del primero de los conceptos. Al soberano no le basta con representar porque, para poder hacerlo, debe antes ne- 
cesariamente decidir qué orden representar: este contenido no le viene ya dado desde arriba. Su representación no lo es de una verdad trascendente sino que, conforme a la especificidad de la Edad Moderna, no aspira a ser más que representación en sentido existencial ${ }^{22}$.

La soberanía tiene tanto de representación (Repräsentation), o de forma jurídica (Rechtsform), como de decisión (Entscheidung): la norma (die Norm, das Normale, die Normalität, der normale Zustand, die Rechtsnorm o der Normalfall) o la regla (die Regel) que representa es sólo posible como resultado de una decisión sobre aquello que, oponiéndose a ella, es sin embargo lo que la explica y aquello de lo que la norma se nutre ${ }^{23}$. Contemplado desde el punto de vista de su relación con el problema de la repraesentatio, el elemento decisionista de la doctrina schmittiana de la soberanía aparece privado de toda pureza, es decir de toda arbitrariedad, ya en 1922 y sin necesidad de esperar a la publicación del ensayo Sobre los tres modos de pensar la ciencia jurídica (1934), en el que Schmitt se aparta explícitamente de toda adhesión incondicional al decisionismo - considerado como una deformación extrema del normativismo del que es cómplice- y opta por seguir el ejemplo de la filosofia hegeliana del Estado, es decir, de Hegel como pensador del orden concreto que subyace a la decisión creadora del ordenamiento jurídico y al que el filósofo suabo se referió como «eticidad» (Sittlichkeit) $)^{24}$. No es el caso, por lo tanto, que en la evolución del pensamiento de Schmitt se dé algo así como una superación de una inicial concepción decisionista de la soberanía en- frentada inicialmente al normativismo, sino que más bien la idea de Konkretordnung y la fidelidad a ella, ciertamente hecha explícita como tal a mediados de los años treinta, ofrece en realidad uno de los hilos conductores del conjunto de la obra schmittiana ${ }^{25}$. Tampoco es el caso, de hecho, que toda Entscheidung jurídico-política presuponga una situación excepcional, sino que para poner de manifiesto la especificidad de la decisión con respecto a la norma Schmitt considera preciso acudir a los momentos en los que la decisión acontece en todo su esplendor, es decir, aquellos que son objeto de estudio histórico por el jurista de Plettenberg en La dictadura (1921). Se trata de la actualización del pouvoir constituant de los pueblos que, como secularización moderna de la concepción medieval de la potestas constituens divina, define Schmitt en su Teoría de la Constitución como sigue:

Poder constituyente es la voluntad política cuya fuerza o autoridad es capaz de adoptar la concreta decisión de conjunto sobre modo y forma de la propia existencia política, determinando así la existencia de la unidad política como un todo ${ }^{26}$.

Que entre 1919, año de publicación de Romanticismo político, y al menos 1927, año de publicación de la primera versión de El concepto de lo político en Archiv für Sozialwissenschaft und Sozialpolitik, Schmitt ponga el acento en la decisión y no tanto en el problema de la representación, salvo en el mencionado caso de Catolicismo romano y forma política, obedece sin lugar a dudas a su enfrenta- 
miento con las teorías positivistas del derecho dominantes en el periodo weimariano que, en su afán formalizador, tendían a olvidar el propio origen «violento» de la República, es decir, el hecho de que ella estaba fundada en una voluntad constituyente, un acto concreto de pacificación e instauración de un orden que la Carta Magna representaba jurídicamente como Grundgesetz, Grundnorm o lex fundamentalis del pueblo alemán ${ }^{27}$. De ello no se desprende, empero, que esta fase del pensamiento schmittiano deba ser tildada de decisionista, al menos no si «decisionismo» se entiende en sentido puro, es decir, como aquella doctrina de la soberanía, paradigmáticamente representada por T. Hobbes, de acuerdo con la cual la decisión soberana surge ex nihilo, de una nada normativa y de una concreta falta de orden, de tal manera que el ordenamiento jurídico por ella establecido no cabe ser explicado ni desde una norma ni desde o encuadrado en un orden concreto, sino como arbitraria fundación tanto de lo uno como de lo otro ${ }^{28}$. A diferencia de este decisionismo puro que Schmitt mienta como Entscheidungsdenken, la decisión en la doctrina schmittiana de la soberanía está siempre referida y limitada por un orden, juridificado -como en el caso de la decisión del juez que dicta sentencia- o no como en el caso de la decisión soberana-.

Respecto del juez, por la propia naturaleza de su cometido, resulta más que obvio que es incapaz de crear orden alguno. Más bien, su función tiene como prerrequisito la existencia de un ordenamiento jurídico a partir del cual debe ser capaz de fundamentar sus sentencias, es decir, de exponer por qué ellas son co- rrectas en las situaciones jurídicas en las que se dictan ${ }^{29}$. No siendo infalible, su actividad se asemeja más a la del servus servorum Dei, el Papa, que a la del Soberano, pues el ius, en su caso positivo y no divino-naturale, le viene dado de antemano. Esto, sin embargo, no significa simplemente, como en el caso del Papa, que la legalidad sea el único criterio de correción de la sentencia de un juez reducido a intérprete -ya de la voluntad de la ley, ya de la voluntad del legislador-y, por lo tanto, de una decisión reducida a subsunción del caso particular bajo la ley ${ }^{30}$. Sin ser legibus solutus, el juez puede decidir correctamente y, sin embargo, hacerlo extra o praeter legem, e incluso contra legem, sin por ello crear derecho ni, sobre todo, suspender el ordenamiento jurídico al que, en la medida en que está sometido al postulado de la determinación del derecho (Rechtsbestimmung) como aquello que explica la necesidad de la praxis jurídica, es decir su propio quehacer, debe apelar inexcusablemente a la hora de fundamentar su dictamen, sea éste secundum, extra o contra legem ${ }^{31}$.

En lo que respecta a la decisión soberana, que sí es legibus soluta y por lo tanto puede suspender in toto un ordenamiento jurídico determinado, no puede decirse de ella, en cambio, que cree un orden como tal sino que, como decisión para la representación, es condición de posibilidad del ser dada al orden concreto pre-jurídico que la precede una forma o configuración jurídica, es decir, normatividad o fuerza de ley. Para ello, en primer lugar, el orden concreto anterior al ordenamiento jurídico debe ser legitimado, en el sentido de reconocido como tal orden, mediante una decisión capaz de distinguirlo 
con respecto a lo informe y desordenado: la excepción. Decidir sobre ésta equivale a decidir sobre lo que se le opone. Decidiendo qué es lo que escapa a la norma se decide al mismo tiempo sobre lo normal, el orden concreto o normalidad fáctica (faktische Normalität) que el ordenamiento jurídico (Rechtsordnung) debe representar-esto es, realizar, en el sentido de conferirle fuerza coactiva o poder (Macht)-. Tal es el sentido del carácter liminar que Schmitt atribuye a la definición jurídica de soberanía como decisión sobre el estado de excepción:

El caso excepcional, en su configuración absoluta, se impone la necesidad de crear una situación dentro de la cual puedan tener validez los preceptos jurídicos. Toda norma general requiere que las relaciones vitales a las cuales ha de ser aplicada efectivamente y que han de quedar sometidas a su regulación normativa, tengan configuración normal. La norma exige un medio homogéneo. Esta normalidad fáctica no es un simple "supuesto externo" que el jurista pueda ignorar; antes bien, es parte de su validez inmanente. No existe una solo norma que fuera aplicable al caos. Es menester que el orden sea restablecido, si el orden jurídico ha de tener sentido. Es necesario de todo punto implantar una situación normal, y soberano es quien con carácter definitivo decide si la situación es, en efecto, normal. El derecho es siempre «derecho de una situación» ${ }^{32}$.

Resulta innegable que, en 1922, esa «situación» o «normalidad fáctica» mienta en la práctica, aun con evidente menor concreción, lo mismo que Konkretordnung en 1934. De este modo, la decisión soberana sobre la excepción resulta tal en orden a arrojar luz sobre el orden prejurídico que el jurídico representa, esto es, dota de fuerza de ley. Relativa a un orden concreto subyacente tanto al derecho como a la decisión, Schmitt niega todo carácter absoluto a esta última: aunque ninguna norma jurídica ejerce poder coactivo alguno sobre ella, su poder está siempre ordenado, valga la redundancia, a un orden previo carente per se de la juridicidad que le es otorgada por el derecho que quiere conservarse $\mathrm{o}$, por el contrario, fundarse mediante la decisión del soberano. Ésta no es efecto de una incomprehensibilis potentia absoluta, sino ordinata: la voluntad que la toma no es voluntas beneplaciti sino conditionata o regulata, de manera que todo lo que hace extra legem o contra legem no deja de ser signo de una ordinatio ubicada más acá del derecho positivo. La potentia de facto del soberano schmittiano lo es también, en cierto sentido, de iure, en la medida en que está limitada por un orden que, de acuerdo con la tesis schmittiana de la secularización, carece de todo carácter trascendente puesto que, propiamente, se da en la pura inmanencia de lo que está ahí antes que el derecho, a saber, la existencia de las comunidades humanas y, más concretamente, de ciertas instituciones -Schmitt aduce la familia o el descanso dominical, pero bien podrían ser otras- que según el jurista han de ser garantizadas por la concreta decisión de conjunto sobre el modo y la forma de la propia existencia política de un pueblo que éste toma para constituirse en unidad política, es decir, como poder constituyente ${ }^{33}$. 


\section{Conclusiones}

Hecho público en 1934, Sobre los tres modos de pensar la ciencia jurídica puede ser leído como un escrito de circunstancias, al igual que deben serlo otros (infames) textos schmittianos de la misma época. Tal y como se ha tratado de mostrar en las páginas precedentes, a partir de la relación entre los conceptos de decisión y representación en el supuesto periodo decisionista del pensamiento schmittiano, la idea central de este trabajo, «orden concreto», sin ser denominada así subyace sin embargo a la definición del soberano formulada por Schmitt en Teología política y, de hecho, lo mismo puede afirmarse con respecto a la distinción «amigo/enemigo»en El concepto de lo político, donde por lo demás el carácter existencial y por lo tanto inmanente del orden prejurídico, sancionado como tal por la decisión y posteriormente representado, es decir dotado de fuerza de ley por el ordenamiento jurídico, es si cabe más enfatizado, acaso dramatizado como posibilidad de matar y ser matado, que en trabajos tanto anteriores como posteriores en el tiempo ${ }^{34}$.

A pesar de la satisfacción mostrada por Schmitt en relación al nacionalsocialismo en las últimas páginas de su ensayo sobre las modalidades del pensamiento jurídico, la idea de «orden concreto» no deja de ser por lo tanto deudora de las de «representación» $\mathrm{y}$ «forma» cuyos orígenes sitúa el jurista en el catolicismo y, por lo tanto, en uno de los enemigos del III Reich. Quizá ello explique la acusación vertida por la Schutzstaffel sobre Schmitt en 1936 a través de su propio semanario, Das schwarze Korps, en el que se le de- nunció tanto por su oportunismo, cargo éste que también le imputaría más tarde $\mathrm{K}$. Löwith, como por su hegelianismo y su vinculación con el catolicismo político ${ }^{35}$. Las tres acusaciones de las SS fueron justas: Schmitt, heredero de la filosofía católica de la contrarrevolución fue asimismo un hegeliano ávido, si no de poder, al menos sí de acceso al poderoso. Cabría incluso explicar la relación de Schmitt con el nacionalsocialismo a partir del motivo arendtiano de la banalidad del mal. Al menos no cabe hacerlo aduciendo motivos ideológicos -si puede hablarse de antisemitismo en Schmitt, se trata de un antisemitismo teológico, a la manera de Marción, y no racista- ni, como espera haberse mostrado, jurídico-políticos. Como no cabe ninguna duda de que su adhesión y apoyo intelectual al NSDAP le catapultó hacia las más altas esferas de la jurisprudencia alemana, al menos, entre 1933 y 1936, siempre bajo la protección de H. Göring.

Respecto del catolicismo político, lo expuesto más arriba ha demostrado que la vinculación de la doctrina schmittiana de la soberanía con la teoría política católica, tal y como Schmitt la postuló en 1922 a través de su definición de «teología política», no fue en modo alguno de carácter dogmático o sustancial, sino funcional o formal -al menos hasta la irrupción de la idea de katechon en su teoría política y la consiguiente teologización de su propuesta inicial-. Aquello que sigue el modelo de algo no se identifica sin más con ello. Aceptando la peculiaridad de su propio tiempo, el intempestivo Schmitt no postuló a su soberano como un servus servorum Dei, a la manera del Papa, sino, ca- 
bría decirlo así, como un servus ordinis saecularis. El Souverän schmittiano lo es en tanto que representante de un orden concreto e inmanente (secular) que precede fácticamente al derecho y al que éste confiere forma jurídica, es decir, fuerza de ley, como resultado de una decisión de carácter existencial no legitimada, por tanto, en razón de trascendencia alguna, sino por la propia vida del pueblo a la que la decisión se ordena para ser genuinamente política: soberana en tanto que representativa del orden concreto pre-jurídico que a ella subyace.

\section{BIBLIOGRAFÍA}

Canziani, G., Granada, M. A. y Zarka Y. Ch. (eds.), Potentia Dei. L'onnipotenza divina nel pensiero dei secoli XVI e XVII, Franco Angeli, Milano, 2000.

Galindo Hervás, A., «Los fundamentos teológicos de la política moderna», en Araucaria. Revista Iberoamericana de Filosofia, Política y Humanidades 12, Sevilla, 2004, pp. 41-66.

Galli, C., Genealogia della politica. Carl Schmitt e la crisi del pensiero politico moderno, il Mulino, Bologna, 2010 [1996'].

Galli, C., La mirada de Jano. Ensayos sobre Carl Schmitt, trad. de M. J. de Ruschi, FCE, 2011.

Herrero, M., El «nomos»y lo político. La filosofia política de Carl Schmitt, EUNSA, Pamplona, 1997.

Herrero, M. (ed.), Carl Schmitt. Posiciones ante el derecho, Tecnos, Madrid, 2012.

Kelsen, H., «¿Por qué obedecer al Derecho?», en ¿Qué es justicia?, trad. de A. Calsamiglia, Ariel, Barcelona, 1991, pp. 183-193.

Kervégan, J. F., Hegel, Carl Schmitt. Lo político: entre especulación y positividad, trad. de A. García Mayo, Escolar y Mayo, Madrid, 2007.
Löwith, K., «El decisionismo ocasional de Carl Schmitt», en Heidegger, pensador de un tiempo indigente. Sobre la posición de la filosofía en el siglo $X X$, trad. de $\mathrm{R}$. Setton, FCE, Buenos Aires, 2006, pp. 4389.

Rivera García, A., «Humanismo, representación y angelología. El conciliarismo de Juan de Segovia», en C. Flórez Miguel - M. Hernández Marcos - R. Albares Albares (eds.), La primera Escuela de Salamanca (1406-1516), Universidad de Salamanca, Salamanca, 2012, pp. 95-113.

Rivera García, A., «Teología política: consecuencias jurídico-políticas de la $P o-$ tentia Dei», en Daimon. Revista de Filosofia 23, Murcia, 2001, pp. 171-184. Schmitt, C., Catolicismo romano y forma política $[C R]$, trad. de P. Madrigal, Tecnos, Madrid, 2000.

Schmitt, C., «Derechos de libertad y garantías constitucionales en la Constitución del Reich», trad. de M. Herrero, en M. Herrero (ed.), Posiciones ante el derecho, Tecnos, Madrid, 2012, pp. 181-242.

Schmitt, C., El valor del Estado y el significado del individuo $[V E]$, trad. de C. Pardo, Centro de Estudios Políticos y Constitucionales, Madrid, 2011. 
Carl Schmitt y el pensamiento del orden concreto: una crítica de la interpretación decisionista...

Schmitt, C., «La era de las neutralizaciones y de las despolitizaciones», en El concepto de lo político. Texto de 1932 con un prólogo y tres corolarios $[C P]$, trad. de A. Maestre, Alianza, Madrid, $2006^{4}$ $\left(1991^{1}\right)$, pp. 107-122.

Schmitt, C., La dictadura desde los comienzos del pensamiento moderno de la soberanía hasta la lucha de clases proletaria, trad. de J. Díaz García, Alianza, Madrid, 2007.

Schmitt, C., «La visibilidad de la Iglesia. Una reflexión escolástica» $[V I]$, trad. de R. García Pastor, en Daimon. Revista de Filosofia 13, Murcia, 1996, pp. 11-18.

Schmitt, C., «Ley y juicio. Examen sobre el problema de la praxis judicial» $[L J$, trad. de M. Herrero, en M. Herrero (ed.), Posiciones ante el derecho, Tecnos, Madrid, 2012, pp. pp. 1-178.
Schmitt, C., Sobre los tres modos de pensar la ciencia jurídica, trad. de M. Herrero, Tecnos, Madrid, 1996.

Schmitt, C., «Teología política. Cuatro capítulos sobre la doctrina de la soberanía» [TP], en Teología política, trad. de F. J. Conde, Trotta, Madrid, 2009, pp. 9-58. Schmitt, C., Teoría de la Constitución [TC], trad. de F. Ayala, Alianza, Madrid, 1982.

Villacañas Berlanga, J. L., «La leyenda de la liquidación de la teología política», en C. Schmitt, Teología política, Trotta, Madrid, 2009, pp. 135-180.

Villacañas Berlanga, J. L., Poder y conflicto. Ensayos sobre Carl Schmitt, Biblioteca Nueva, Madrid, 2008.

Voegelin, E., La nueva ciencia de la politica. Una introducción, trad. de J. Ibarburu, Katz, Buenos Aires, 2006.
${ }^{1}$ Cf. Schmitt, C., «Teología política. Cuatro capítulos sobre la doctrina de la soberanía» [TP], en Teología politica, trad. de F. J. Conde, Trotta, Madrid, 2009, pp. 37 ss.

${ }^{2}$ Cf. Ar., Pol., 1253a.

${ }^{3} \mathrm{Cf}$. Schmitt, C., «La era de las neutralizaciones y de las despolitizaciones», en El concepto de lo político. Texto de 1932 con un prólogo y tres corolarios $[C P]$, trad. de A. Maestre, Alianza, Madrid, 20064 (1991'1), pp. 107-122.

${ }^{4} \mathrm{TP}, 13$. Sobre los sentidos prognóstico, diagnóstico y terapéutico de la teología política schmittiana, cf. Galli, C., La mirada de Jano. Ensayos sobre Carl Schmitt, trad. de M. J. de Ruschi, FCE, 2011, pp. 61 ss.

${ }^{5} \mathrm{TP}, 37$.

${ }^{6}$ Cf. Galindo Hervás, A., «Los fundamentos teológi$\cos$ de la política moderna», en Araucaria. Revista Iberoamericana de Filosofia, Política y Humanidades 12, Sevilla, 2004, pp. 41-66, así como Galli, C. La mirada de Jano..., cit., p. 28 ss.

${ }^{7}$ Cf. Canziani, G. - Granada, M. A. - Zarka Y. Ch. (eds.), Potentia Dei. L'onnipotenza divina nel pensiero dei secoli XVI e XVII, Franco Angeli, Milano, 2000, Rivera García, A., «Teología política: consecuencias jurídico-políticas de la Potentia Dei», en Daimon. Revista de Filosofia 23, Murcia, 2001, pp. 171-184 y Villacañas Berlanga,
J. L., Poder y conflicto. Ensayos sobre Carl Schmitt, Biblioteca Nueva, Madrid, 2008, pp. 151 y 260 e Id., «La leyenda de la liquidación de la teología política», en $T P, 155$.

${ }^{8}$ Cf. Schmitt, C., Teoría de la Constitución [TC], trad. de F. de Ayala, Alianza, Madrid, 1982, pp. 205 ss.

${ }^{9}$ Sobre la distinción entre representación en «sentido elemental» (elemental sense), en cuyo plano permanece ideológicamente el parlamentarismo, y en «sentido existencial» (existential sense), al que debe restringirse una concepción verdaderamente crítica de lo político, cf. Voegelin, E., La nueva ciencia de la política. Una introducción, trad. de J. Ibarburu, Katz, Buenos Aires, 2006, pp. 41-68. Sobre la relación entre «identidad» (Identität) y «representación» (Repräsentation), así como sobre el carácter existencial de esta última en la teoría política schmittiana, cf. TC, 205-209. Por último, respecto de los diferentes sentidos latinos de repraesentatio (similitudinis, potestatis, naturalis e identitatis), cf. Rivera García, A., «Humanismo, representación y angelología. El conciliarismo de Juan de Segovia», en C. Flórez Miguel - M. Hernández Marcos - R. Albares Albares (eds.), La primera Escuela de Salamanca (1406-1516), Universidad de Salamanca, Salamanca, 2012, pp. 95 ss.

${ }^{10}$ Cf. TC, $80-81$ y $85-86$. 
${ }^{11} T C, 87$. Sobre la fórmula pacta sunt servanda como fundamento de validez del derecho en el positivismo jurídico, cf. Kelsen, H., «¿Por qué obedecer al Derecho?», en ¿Qué es justicia?, trad. de A. Calsamiglia, Ariel, Barcelona, 1991, pp. 183-193.

${ }^{12}$ Cf. TP, 49-58, así como Galli, C., La mirada de Jano..., cit., pp. 85-86.

${ }^{13} \mathrm{Cf}$. Schmitt, C., El valor del Estado y el significado del individuo [VE], trad. de C. Pardo, Centro de Estudios Políticos y Constitucionales, Madrid, 2011, pp. 13-58.

${ }^{14}$ Cf. Schmitt, C., Catolicismo romano y forma política $[C R]$, trad. de P. Madrigal, Tecnos, Madrid, 2000, p. 5.

${ }^{15}$ Cf. $C R, 23$.

${ }^{16} \mathrm{Cf}$. $C R, 9$. Con toda seguridad, Schmitt está aquí aludiendo de manera soterrada a una de sus lecturas existencialistas de juventud: Enten-Eller (en alemán, precisamente, Entweder-Oder) de S. Kierkegaard, a quien también cita Schmitt, de nuevo sin nombrarle, al final del primero de los capítulos de Teología política (cf. TP, 20).

${ }^{17}$ Cf. Galli, C., La mirada de Jano..., cit., p. 64, nt. 11, así como Id., Genealogia della politica. Carl Schmitt e la crisi del pensiero politico moderno, il Mulino, Bologna, $2010^{2}$ [1996'1], pp. 229-280.

${ }^{18} \mathrm{Cf}$. Schmitt, C., «La visibilidad de la Iglesia. Una reflexión escolástica» $[V I]$, trad. de R. García Pastor, en Daimon. Revista de Filosofia 13, Murcia, 1996, pp. 14-15. La distinción está también sugerida en el Habilitationschrift. Cf. VE, 66.

${ }^{19}$ De esta crítica de la labor representativa del papa no extrae Schmitt, como sin embargo podría haber hecho, consecuencia conciliarista alguna, es decir, justificación alguna de la superioridad de la congregatio fidelium representada como un todo orgánico por el concilio, siquiera precisamente en los casos de extrema necessitas en los que, originalmente, surgió esta democratizadora corriente antipapalista de raigambre paulina cuya versión secularizada ofrece el parlamentarismo moderno denostado por Schmit: momentos de sede apostólica vacante, ya sea por fallecimiento o renuncia del papa, o de crisis institucional como la suscitada por Eugenio IV (1431-1447), condenado como hereje y depuesto en 1439 por el Concilio de Basilea (1431-1449), que nombró como sucesor suyo al Duque Amadeo VIII de Saboya (1383-1451), el anti-papa Félix V (1439-1449). Cf. Rivera García, A., «Humanismo, representación y angelología..., cit., pp. 95-113.

${ }^{20}$ Cf. VI, 15-16.

${ }^{21}$ Cf. Galli, C., La mirada de Jano..., cit., pp. 68 ss.

${ }^{22}$ Sobre esta distinción, cf. Voegelin, E., La nueva ciencia de la política ..., cit., pp. 41-96.

${ }^{23} T P$, 20: «La excepción es más interesante que el caso normal. Lo normal nada prueba; la excepción, todo; no sólo confirma la regla, sino que ésta vive de aquella».

${ }^{24} \mathrm{Cf}$. Schmitt, C., Sobre los tres modos de pensar la ciencia jurídica, trad. de M. Herrero, Tecnos, Madrid,
1996, pp. 26-44 y 51-53. Sobre la relación de Schmitt con Hegel, véase también Galli, C., Genealogia della politica ..., cit., pp. 13-33, así como Kervégan, J. F., Hegel, Carl Schmitt. Lo politico: entre especulación y positividad, trad. de A. García Mayo, Escolar y Mayo, Madrid, 2007.

${ }^{25}$ Cf. Galli, C., La mirada de Jano..., cit., p. 48, así como Herrero, M., El «nomos» y lo político. La filosofía política de Carl Schmitt, EUNSA, Pamplona, 1997 e Id., «Estudio preliminar», en Id. (ed.), Posiciones ante el derecho, Tecnos, Madrid, 2012, pp. XXXV-XXXVI.

${ }^{26}$ TC, 93-94. Véase también Schmitt, C., La dictadura desde los comienzos del pensamiento moderno de la soberanía hasta la lucha de clases proletaria, trad. de J. Díaz García, Alianza, Madrid, 2007.

${ }^{27}$ El concepto «norma fundamental» no debe ser aquí entedido en sentido lógico-jurídico, es decir como presupuesto metajurídico, metapositivo y trascendental que fundamenta la pirámide normativa, forma a priori de la juridicidad, a la manera de la teoría pura del derecho de $\mathrm{H}$. Kelsen. Pero tampoco como «ley constitucional» (Verfassungsgesetz), sino como: «Constitución en sentido positivo, de donde la llamada ley fundamental no tiene por contenido esencial una normación legal, sino la decisión política» $(T C, 64)$. Sobre el concepto positivo de «Constitución», es decir como resultado de la actualización del poder constituyente en el sentido antes referido, cf. TC, 4557.

${ }^{28}$ Cf. Schmitt, C., Sobre los tres modos ..., cit., pp. 2931, así como Galli, C., La mirada de Jano..., cit., p. 48.

${ }^{29} \mathrm{Cf}$. Schmitt, C., «Ley y juicio. Examen sobre el problema de la praxis judicial» [LJ], trad. de M. Herrero, en M. Herrero (ed.), Posiciones..., cit., pp. 96 ss.

${ }^{30}$ Cf. $L J, 41-68$.

${ }^{31}$ Cf. $L J, 69-159$.

${ }^{32} \mathrm{TP}, 18$.

${ }^{33}$ Cf. TC, 175-179, así como Schmitt, C., «Derechos de libertad y garantías constitucionales en la Constitución del Reich», trad. de M. Herrero, en Id. (ed.), Posiciones..., cit., pp. 181-242.

${ }^{34} \mathrm{Cf} . C P, 56 \mathrm{ss}$.

${ }^{35}$ Cf. Löwith, K., «El decisionismo ocasional de Carl Schmitt», en Heidegger, pensador de un tiempo indigente. Sobre la posición de la filosofia en el siglo $X X$, trad. de $\mathrm{R}$. Setton, FCE, Buenos Aires, 2006, pp. 43-89. Cf. también Galli, C., La mirada de Jano..., cit., p. 49. 